\section{Diffuse retinal pigment epitheliopathy complicating systemic corticosteroid treatment}

\author{
Bettine C P Polak, G Seerp Baarsma, Bernadette Snyers
}

\begin{abstract}
Aims/Background-This study was undertaken to confirm the association between diffuse retinal pigment epitheliopathy (DRPE) and systemic corticosteroid therapy. This finding can be of help in determining an aetiological factor in DRPE and associated diseases. Corticosteroids may contribute to the development of leakage in the presence of a retinal pigment epitheliopathy or central serous chorioretinopathy.
\end{abstract}

Methods-Cases of DRPE were collected from the files of members of the European Fluorescein Angiography Club. There were 34 who developed their ophthalmic symptoms while being treated with corticosteroids

Results-DRPE developed in 34 patients from 10 European eye clinics during systemic treatment with corticosteroids. Thirteen patients were treated with corticosteroids after allotransplantation, 21 other patients developed ocular symptoms while treated with steroids for serious systemic disorders. Symptoms occurred in some patients when the daily corticosteroid dosage was elevated, and the visual complaints ameliorated or even disappeared sometimes on discontinuation of the corticosteroid therapy.

Conclusion-Corticosteroids can damage the retinal pigment epithelial barrier and predispose a patient to serous retinal detachment, whereas psychological stress may play a role in the development of central serous chorioretinopathy. A decrease of the daily corticosteroid dosage may help to diminish the visual symptoms.

(Br f Ophthalmol 1995; 79: 922-925)

Hospital, the

B C P Polak

G Seerp Baarsma

Institute of

Ophthalmology,

University Hospital,

Nijmegen, the

Netherlands

B C P Polak

Department of

Ophthalmology,

University Hospital

Saint-Luc, Brussels,

Belgium

B Snyers

Correspondence to: The Rotterdam Eye Hospital, PO Box 70030 3000 LM Rotterdam, the Netherlands.

Accepted for publication 27 June 1995

Diffuse retinal pigment epitheliopathy (DRPE) or chronic central serous retinopathy resembles both acute central serous chorioretinopathy and pigment epithelial detachment, but can be differentiated by the following characteristic features: widespread distribution of small pigment epithelial detachments, only a few funduscopically pigment epithelial alterations in the presence of more extensive pigmentary changes with variable leakage on the fluorescein angiogram, chronic course with exacerbations and remissions, often bilateral in appearance, fair visual outcome in most patients usually with remaining disturbance of colour vision and troublesome metamorphopsia. ${ }^{2}$ Bettine C P Polak, MD,

Differential diagnosis can only be made fluorographically, whereas borderline cases do occur. The differences between diffuse retinal pigment epitheliopathy on the one hand and pigment epithelial detachment and acute central serous chorioretinopathy on the other are quantitative rather than qualitative. The major distinction between chronic and acute disease is the fact that chronic disease has widespread pigment epithelial changes without overt detachment in most cases, whereas in acute disease there is focal pigment epithelial abnormality and marked detachment.

The disorders may be asymptomatic if the fovea is not involved or if the disease occurs in the non-dominant eye. In most patients major visual symptoms resolve after a few months, but small funduscopically visible pigment epithelial alterations usually remain as well as complaints of metamorphopsia, micropsia, colour vision changes, and/or darkening of the central visual field. Central serous chorioretinopathy following systemic corticosteroids has been recorded previously. $^{3}$ Several authors reported the occurrence of central serous chorioretinopathy or serous retinal detachment after organ transplantation, when stress factors in combination with immunosuppressive therapy are present and may play a role in the development of the ocular symptoms. ${ }^{4-6}$ These findings were discussed within the European Fluorescence Angiography Club together with similar observations by one of us in patients with systemic disorders and therapy with corticosteroids. We collected as many patients as possible with these ophthalmic findings complicating systemic corticosteroid treatment.

Patients and methods

The members of the European Fluorescein

Angiography Club agreed to collect from their clinical files and photographic and fluoroangiographic documentation patients with the diagnosis of DRPE, who developed their ophthalmic symptoms while being treated with corticosteroids: 10 Belgian patients, 18 Dutch patients, five French patients, and one German patient could be diagnosed as such.

The diagnosis was made according to the following criteria, based on the clinical manifestations as described by Zweng and Little: widespread distribution of small pigment epithelial detachments, extensive pigmentary changes, chronic course with exacerbations and remissions. ${ }^{1}$ 
Table 1 Survey of the patients who developed diffuse retinal pigment epitheliopathy or chronic central serous chorioretinopathy during corticosteroid therapy after transplantation

\begin{tabular}{|c|c|c|c|c|c|c|c|}
\hline \multicolumn{2}{|c|}{ Eye clinic } & Sex & $\begin{array}{l}\text { Age } \\
\text { (years) }\end{array}$ & $\begin{array}{l}\text { Transplanted } \\
\text { organ }\end{array}$ & $\begin{array}{l}\begin{array}{l}\text { Daily } \\
\text { dosage } \\
(m g)\end{array} \\
12.5\end{array}$ & $\begin{array}{l}\begin{array}{l}\text { Duration } \\
\text { of therapy } \\
\text { (months) }\end{array} \\
4\end{array}$ & $\begin{array}{l}\text { Antihypertensive } \\
\text { treatment }\end{array}$ \\
\hline $\begin{array}{r}1 \\
2 \\
3 \\
4 \\
5 \\
6 \\
7 \\
8 \\
9 \\
10 \\
11 \\
12 \\
13\end{array}$ & $\begin{array}{l}\text { Leuven } \\
\text { Paris } \\
\text { Albi } \\
\text { Rotterdam }\end{array}$ & $\begin{array}{l}M \\
F \\
M \\
M \\
M \\
M \\
F \\
M \\
F \\
M \\
M \\
M \\
M\end{array}$ & $\begin{array}{c}38 \\
35 \\
44 \\
37 \\
37 \\
49 \\
52 \\
? \\
32 \\
43 \\
42 \\
48 \\
48\end{array}$ & $\begin{array}{l}\text { Kidney } \\
\text { Kidney } \\
\text { Kidney } \\
\text { Kidney } \\
\text { Kidney } \\
\text { Kidney } \\
\text { Kidney } \\
\text { Kidney } \\
\text { Kidney } \\
\text { Kidney } \\
\text { Kidney } \\
\text { Liver } \\
\text { Heart }\end{array}$ & $\begin{array}{l}12 \cdot 5 \\
10 \\
10 \\
12 \cdot 5 \\
10 \\
8 \\
15 \\
? \\
10 \\
10 \\
10 \\
15 \\
15\end{array}$ & $\begin{array}{c}4 \\
2 \\
10 \\
1 / 4 \\
2 \\
12 \\
84 \\
24 \\
108 \\
4 \\
6 \\
3 \\
11\end{array}$ & $\begin{array}{l}+ \\
+ \\
+ \\
+ \\
+ \\
+ \\
+\end{array}$ \\
\hline \multicolumn{8}{|c|}{ Total $10+3=13$ patients } \\
\hline
\end{tabular}

\section{Results}

Thirteen patients developed DRPE or chronic central serous chorioretinopathy during corticosteroid therapy after allotransplantation (Table 1), and 21 patients while being treated with prednisone for systemic diseases (Table 2). Several patients developed visual complaints when the daily corticosteroid dosage was elevated (cases 1, 7, 12, and 20; Table 2; Figs 1-5). In three patients recovery accompanied a reduction in steroid treatment to a low level (cases 7, 12, and 20; Table 2, Figs 3-5). The multifocal nature of the chorioretinopathy is evident from the figures shown. All transplanted patients - except the only female kidney transplant recipient - were treated with azathioprine (Imuran) and also cyclosporin. Out of the 13 transplanted patients seven were also treated for hypertension (Table 1), whereas five patients of the 21 with systemic diseases needed antihypertensive treatment in combination with the corticosteroids (Table 2).

The ages of the transplanted patients varied from 32 to 52 years (mean 40 years), those of the patients with systemic disorders from 37 to 68 years (mean 52 years) (see Table 3). Nineteen patients developed DRPE or chronic central serous chorioretinopathy in one eye, and 15 patients had pigmentary epithelial changes in both eyes.
Two eyes within the transplanted group and four eyes within the other group of patients reached a final visual acuity of $0 \cdot 1$ or less (Table 3).

\section{Discussion}

Diffuse retinal pigment epitheliopathy or chronic central serous chorioretinopathy complicating systemic corticosteroid treatment was found in the patients collected by the members of the European Fluorescein Angiography Club. Since the cases have been derived from a very large European population, we cannot exclude the fact that the finding is by chance alone.

Several patients however developed visual complaints when the daily corticosteroid dosage was elevated and recovery accompanied a reduction in steroid treatment to a low level, as could be confirmed by the observations in some of our patients (see cases 1, 7, 12, and 20; Table 2). These findings suggest a possible relation between DRPE or chronic central serous chorioretinopathy and treatment with systemic corticosteroids.

The fact that the form of central serous chorioretinopathy is different from that seen most commonly - namely, acute disease, may reinforce the argument that there is a causal relation between the steroids and the fundus changes. Three out of 60 patients with endogenous Cushing's syndrome had one or more episodes of central serous chorioretinopathy while plasma cortisol levels were high. ${ }^{7}$ Furthermore, the disease has been modelled experimentally in primates using prolonged infusions of intravenous noradrenaline. ${ }^{89}$ Two of our patients were treated with oral prednisone because of symptoms of a neuritis retrobulbaris and also developed a DRPE (Table 2). Similar findings have been described by other authors, and in one patient the central serous chorioretinopathy recurred three times during three separate courses of treatment. ${ }^{3}$

Central serous chorioretinopathy is a recognised complication of pregnancy. ${ }^{10-13} \mathrm{~A}$ possible effect of endogenous corticosteroids

Table 2 Survey of the patients who developed diffuse retinal pigment epitheliopathy or chronic central serous chorioretinopathy while being treated with corticosteroids for systemic diseases

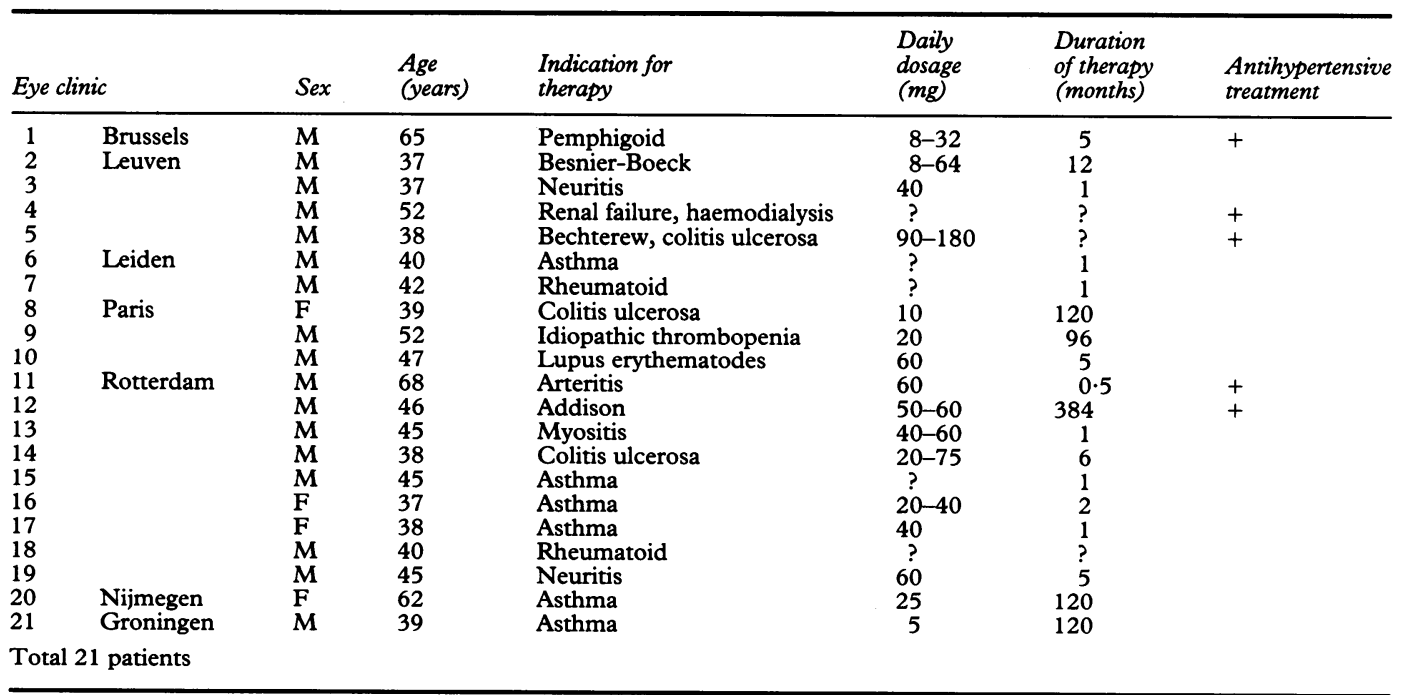




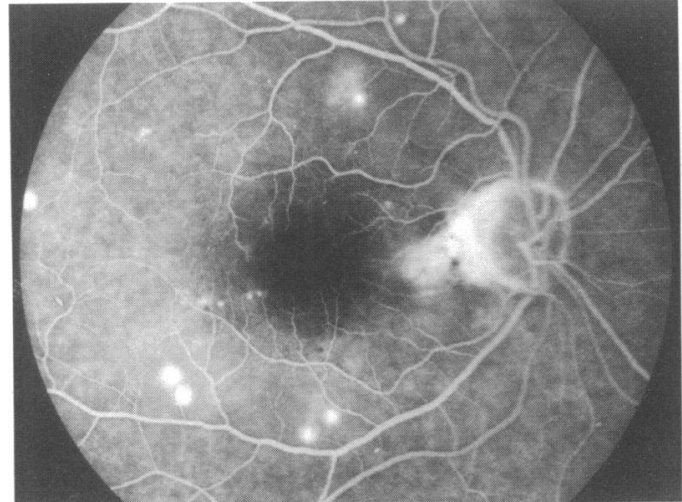

Figure 1 Multiple serous detachments in the right eye of a male patient with pemphigoid (case 1, Table 2). Visual complaints developed in both eyes after $32 \mathrm{mg}$ methylprednisolone a day.

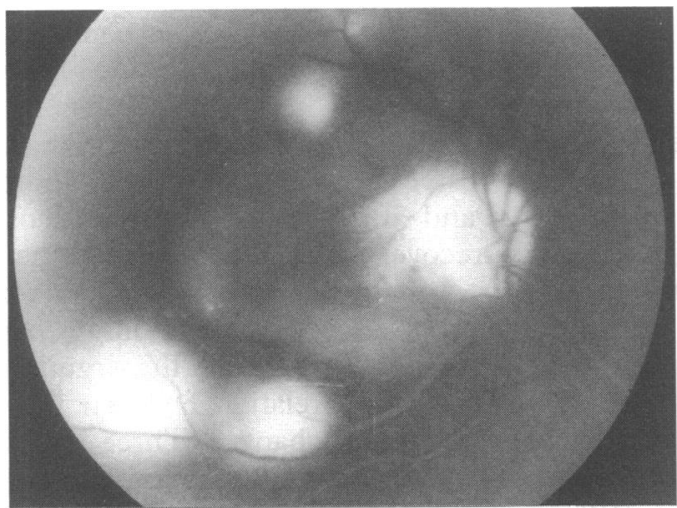

Figure 2 Increasing leakage during the late phase of the fluorogram (case 1, Table 2) of the right eye in the same patient as in Figure 1.

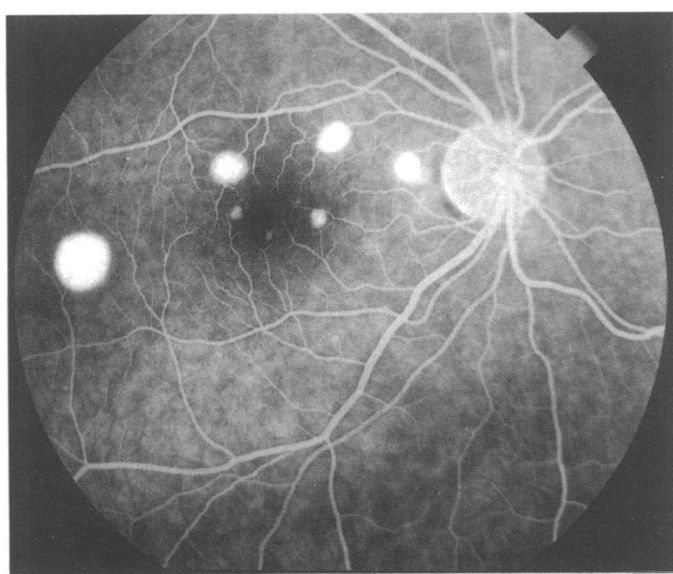

Figure 3 Multiple areas of retinal detachment in the right eye (case 12, Table 2) of a male patient with Addison's disease. Ophthalmic symptoms developed while the patient treated himself with $120 \mathrm{mg}$ prednisone a day. The fluorographic visible leakage disappeared when the prednisone dosage was reduced to $60 \mathrm{mg}$ a day.

during pregnancy on the posterior bloodocular barrier has been suggested, since two attacks of central serous chorioretinopathy developed in one patient during two successive pregnancies and even four attacks in another patient during four pregnancies, each attack resolving spontaneously after delivery or spontaneous abortion. ${ }^{1013}$ The multifocal nature of the leakage, as has been found in our patients, was indeed also seen in pregnancy.

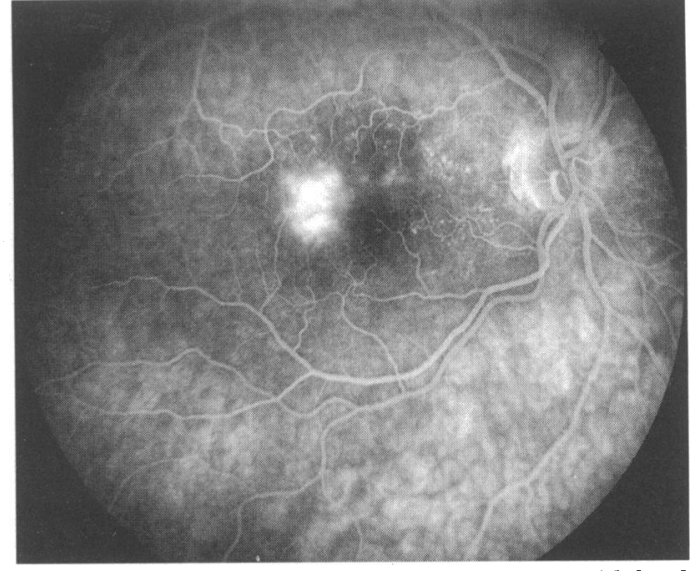

Figure 4 Multiple pigment epithelial alterations with local leakage of fluorescein in the right eye of a female patient with chronic asthma (case 20, Table 2). Visual acuity decreased during an episode with exacerbation, while the daily prednisone dosage was increased.

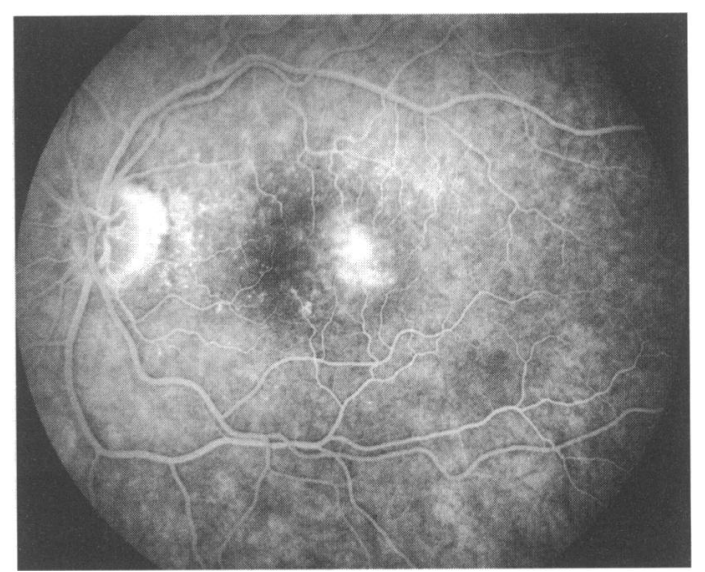

Figure 5 Symptoms of pigment epithelial damage and leakage in the left eye (case 20, Table 2) of the same patient as in Figure 4. When the daily prednisone dosage was decreased there was fluorographically less leakage of fluorescein in both eyes, while the visual symptoms ameliorated.

Table 3 Summary of the findings in 34 patients with diffuse retinal pigment epitheliopathy or chronic central serous chorioretinopathy complicating systemic corticosteroid treatment

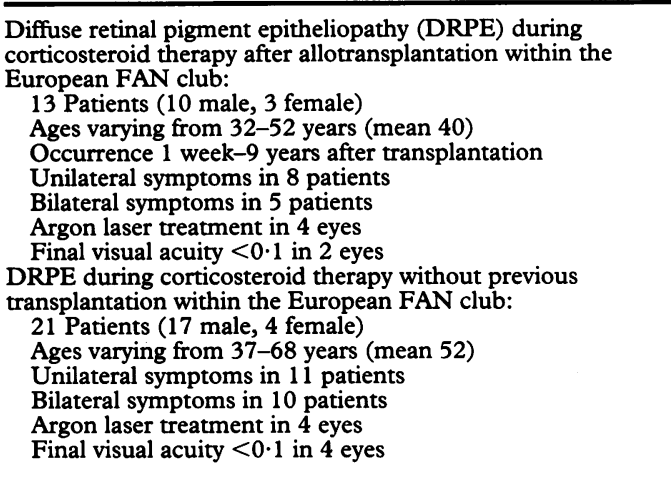

The possible aetiological role of hyperactivity of the adrenomedullary system is sustained by the development of central serous chorioretinopathy especially in patients with a type A behaviour pattern, associated with increased catecholamine secretion. ${ }^{14}$ There is doubtless a strong genetic factor which decrees that some subjects respond to either pleasurable or unpleasant stress in an inappropriate way, thus displaying pathological anxiety or 
stress. ${ }^{15}$ DRPE and central serous chorioretinopathy seem also to be genetically related, since in one family one brother had a DRPE, one sister had a typical central serous chorioretinopathy and the other brother had DRPE in one eye with recurrent central serous chorioretinopathy in the other eye. ${ }^{2}$ Furthermore, central serous chorioretinopathy has also been described in a pair of identical twins. ${ }^{16}$

Until now several authors have suggested that corticosteroids can damage the retinal pigment epithelial barrier and predispose a patient to serous retinal detachment, but convincing evidence that any of these drugs directly contributes to the development of central serous chorioretinopathy and associated diseases was lacking so far. ${ }^{31718}$ Psychological stress may have played a key role in the development of a DRPE or chronic central serous chorioretinopathy in our patients, but the simultaneous administration of prednisone may certainly have influenced the final visual outcome, especially since the ophthalmic symptoms decreased in some patients when the daily prednisone dosage was diminished.

Each of our transplanted patients - except one - also used other immunosuppressive agents such as azothioprine and cyclosporin, whereas some other drugs were used as well by the other patients treated for systemic disorders. None of these drugs, however, is known so far to be involved in the development of chorioretinal changes.

The findings in our patients differ from the leopard-like geographical areas of disruption and coarse clumping of the pigment epithelium in the posterior fundi, observed in some posttransplant patients. ${ }^{19}$ Localised choroidal intravascular coagulation is the suspected but unproved cause of the pigment epithelial changes in those patients. However, choroidal vascular changes have been described before in haemodialysis and kidney transplantation patients, which changes may promote the development of pigment epithelium defects. ${ }^{1920}$ Pigment epithelial alterations are seen in some patients with hypertension, and the fact that 12 of our patients were hypertensive might have promoted the development of a DRPE or chronic central serous retinopathy. In these 12 patients the use of corticosteroids also may have worsened their hypertension, so the pigment epithelial alterations in these patients can be directly as well as indirectly attributed to the corticosteroid treatment.

Both $\beta$ blocking agents propranolol and atenolol modify type $\mathrm{A}$ behaviour, and the use of these drugs has been mentioned as a useful therapy in patients with a central serous chorioretinopathy. ${ }^{15}$ Five of the 12 patients who were treated with antihypertensives did actually get betalytic agents as well as corticosteroids when they developed a DRPE or chronic central serous chorioretinopathy
(Tables 1 and 2). In many diseases the steroid treatment may be life saving and the possible susceptibility of the patient to central serous chorioretinopathy does not represent a contraindication for therapy.

Corticosteroid therapy has been widely used for the treatment of central serous chorioretinopathy and associated disorders. The findings in our patients in contrast make clear that caution should be exercised when corticosteroids are used in certain patients susceptible to develop these diseases: corticosteroids may give rise to symptoms of DRPE or chronic central serous chorioretinopathy instead of diminishing them, whereas recovery may occur when the daily dosage is lowered.

This paper is the result of a collaboration within the European Fluorescein Angiography Club.

The authors wish to thank the following members of the European Fluorescein Angiography Club, who kindly agreed to European Fluorescein Angiography Club, who kindly agreed to
send their clinical data: P Amalric (Albi, France); J A Bernard (Paris, France); A Bird, A M Hamilton, J Shilling (London, (Paris, France); A Bird, A M Hamilton, J Shilling (London, Great Britain); G Chaine (Paris, France); G Coscas and G
Soubrane (Créteil, France); A F Deutman (Nijmegen, the Netherlands); J Hooymans and Z Timmermans (Groningen, the Netherlands); J J de Laey and H A Priem (Gent, Belgium); A Leys (Leuven, Belgium); J A Oosterhuis and R Borsje (Leiden, the Netherlands); C Verougstraete (Brussels, Belgium); and A Wessing (Essen, Germany).

1 Zweng HC, Little HL. Diffuse retinal pigment photocoagulation. St Louis: Mosby, 1977: 117-26.

2 Winning CHOM von, Oosterhuis JA, Renger-van Dijk AH, Hornstra-Limburg H, Polak BCP. Diffuse retinal pigment epitheliopathy. Ophthalmologica 1982; 185: 7-14.

3 Gass JDM. Stereoscopic atlas of macular diseases: diagnosis and treatment. 3rd ed. St Louis: Mosby Year Book, 1987: 46-59.

4 Snyers B, Kestens C. Choroidite sereuse centrale après transplantation rénale. Bull Soc Belge Ophtalmol 1990; 239: 87-101.

5 Friberg ThR, Eller AW. Serous retinal detachment resembling central serous chorioretinopathy following organ transplantation. Graefes Arch Clin Exp Ophthalmol organ transplantation.

6 Wakakura $M$, Ishikawa $S$. Central serous chorioretinopathy complicating systemic corticosteroid treatment. $\mathrm{Br} F$ Ophthalmol 1984; 68: 329-31.

7 Bouzas EA, Scott MH, Mastorakos G, Chrousos GP, Kaiser-Kupfer MI. Central and serous chorioretinopathy in endogenous hypercortisolism. Arch Ophthalmol 1993; 111: 1229-33.

8 Yoshioka H, Katsume Y. Experimental central serous chorioretinopathy. III. Ultrastructural findings. $\mathscr{f p n} \mathfrak{f}$ Ophthalmol 1982; 26: 397-409.

9 Yoshioka H, Katsume Y, Akune H. Experimental central serous chorioretinopathy in monkey eyes. Fluorescein angiographic findings. Ophthalmologica 1982; 185: 168-78.

10 Cruysberg JRM, Deutman AF. Visual disturbances during pregnancy caused by central serous choroidopathy. $B r \mathcal{F}$ Ophthalmol 1982; 66: 240-1.

11 Gass JDM. Central serous chorioretinopathy and white subretinal exudation during pregnancy. Arch Ophthalmol 1991; 109: 677-81.

12 Sunness JS, Haller JA, Fine SL. Central serous chorioretinopathy and pregnancy. Arch Ophthalmol 1993; 111: $360-4$.

13 Chumbley LC, Frank RN. Central serous retinopathy and pregnancy. Am f Ophthalmol 1974; 77: 158-60

14 Yannuzzi LA. Type A behavior and central serous chorioretinopathy. Trans Am Ophthalmol Soc 1986; 84: 799-845.

15 Cruickshank JM, Prichard BNC. Beta-blockers in clinical practice. Edinburgh: Churchill Livingstone, 1987.

16 Jonkers GH. Central serous retinopathy in a monozygotic twin pair. Acta Genet Med Gemellol Roma 1960; 9: 438.

17 Jain IS, Singh K. Maculopathy, a corticosteroid side effect. All-India Ophthalmol Soc 1966; 14: 250.

18 Williamson J, Nuki G. Macular lesions during systemic therapy with depot tetracosactrin. Br f Ophthalmol 1970; 54: 405-9.

19 Gass JDM, Slamovits ThL, Fuller DG, Gieser RG, Lean JS. Posterior chorioretinopathy and retinal detachment after organ transplantation. Arch Ophthalmol 1992; 110: 1717-22

20 Polak BCP. Ophthalmological complications of haemodialysis and kidney transplantation. Doc Ophthalmol 1980; 49: 1-96. 